\title{
Laparoscopic minor pancreatic resections (enucleations/atypical resections). A long-term appraisal of a supposed mini-invasive approach
}

\author{
Renato Costi ${ }^{1,2}$, Bruto Randone ${ }^{1}$, Frédérick Mal ${ }^{1}$, Silvia Basato ${ }^{1}$, Hugues Levard ${ }^{1}$, Brice Gayet ${ }^{1}$ \\ 1Département de Pathologie Digestive, Institut Mutualiste Montsouris, Paris, France \\ 2Dipartimento di Scienze Chirurgiche, Università degli Studi di Parma, Parma, Italia
}

Videosurgery Miniinv 2013; 8 (2): 117-129

DOI: 10.5114/wiitm.2011.32863

\begin{abstract}
Introduction: A few retrospective, small, often multicentric studies show encouraging results of laparoscopic minor pancreatic surgery, but do not allow for an evaluation of feasibility and effectiveness.

Aim: Evaluation of the results of laparoscopic minor pancreatic resections (LMPR), including atypical resections and enucleations.

Material and methods: The outcome of all consecutive patients undergoing LMPR in a tertiary care university hospital specializing in the laparoscopic approach to solid organs (I.M.M., Paris - France) was retrospectively evaluated by the analysis of operating time, blood loss, conversion, morbidity, stay and late outcome.

Results: Thirty-three patients underwent LMPR (29 enucleations and 4 atypical resections) for various diseases. The conversion rate was 21\%, mean operating time $189 \mathrm{~min}$, and mean blood loss $133 \mathrm{ml}$. Morbidity was $60 \%$; 10 patients (30\%) presented a pancreatic fistula. Pancreatic fistula was independent of type of resection, technique of pancreas section, management of enucleated surface and somatostatin administration. Median stay for enucleations was 18 days. Mean follow-up was 61 months.

Conclusions: Laparoscopic pancreatic enucleation is feasible and safe, with no mortality, no lengthening of operating time and a high success rate. Conversely, it does not imply a reduction in complications or hospital stay at the present state of the art.
\end{abstract}

Key words: laparoscopy, pancreas, treatment outcome, morbidity, pancreatic fistula.

\section{Introduction}

Traditionally considered a difficult organ to approach surgically, owing to its retroperitoneal location, its connections with major vessels and the intrinsic characteristics of its parenchyma, the pancreas has been considered for years one of the "last frontiers" of laparoscopic surgery. Nevertheless, almost two decades after the first laparoscopic pancreatectomy [1], the laparoscopic approach to the pancreas is slowly spreading in specialized environments [2-6]. Whereas laparoscopic procedures involving resection of the head of the pancreas (pancreatoduodenectomy (PD), total PD) still represent a major challenge even for experienced laparoscopic surgeons, enucleations/ atypical resections are increasingly performed worldwide [3-5, 7-10].

Pancreatic enucleations, mostly performed for small, benign pathologies, are increasingly consid- 
ered ideal procedures to accomplish laparoscopically. Nevertheless, the real feasibility and effectiveness of laparoscopic enucleations/atypical pancreatic resections have yet to be assessed. Also owing to the rarity of pancreatic affections suitable for laparoscopic enucleation, papers reported in the literature are mostly few-case reports $[6,11-13]$ or small series $[4,5$, 7-10], the most important one reporting a retrospective, multicentric series of 24 patients [4]. Owing to their small population size and short follow-up, these papers still do not allow for a critical appraisal of the short- and long-term outcome of this approach.

\section{Aim}

With the purpose of evaluating the results of laparoscopic pancreatic minor surgery, here we present the short- and long-term results (5-year mean followup) of a monocentric series of 33 patients undergoing laparoscopic pancreatic enucleation/atypical resection over a 15-year period in a center specializing in the laparoscopic approach to abdominal solid organs $[14,15]$, including pancreatic surgery $[16,17]$.

\section{Material and methods}

Prospectively collected demographic, clinical, preoperative and intraoperative data and postoperative outcome of all patients undergoing minor pancreatic resections (enucleations, atypical pancreatic resections) at Institut Mutualiste Montsouris were retrospectively analyzed. The evaluation of short- and long-term results of surgery was performed by the analysis of intraoperative parameters (operating time, blood loss, conversion to laparotomy), perioperative morbidity (with particular emphasis on pancreatic fistula), hospital stay and late outcome. Enucleation is defined as the extirpation of a pancreatic mass by dissection of the mass itself from the surrounding pancreatic parenchyma; atypical resection is defined as the extirpation of a pancreatic mass by non-anatomical section of the pancreatic parenchyma; simple enucleation is defined as an enucleation carried out without any other synchronous major surgical act (oesophagectomy, hepatectomy, etc.), regardless of other minor surgical procedures (minor adhesiolysis, etc.); complex procedure is defined as an atypical resection or an enucleation associated with major procedures. The extirpated mass is defined as tumor, regardless of the (benign or malignant) nature of the neoplasia. Complications are defined according to the Clavien-Dindo classification [18]; pancreatic fistula (PF) is defined according to the recent consensus conference of the International Study Group of Pancreatic Fistula (ISGPF) [19]. The patients were contacted in February-March 2011 in order to complete the long-term follow-up.

The analysis of operating time, blood loss, perioperative morbidity and hospital stay was performed considering both the whole series and the subgroup of patients undergoing simple enucleations. Such an analysis was aimed at allowing for a more precise evaluation of intraoperative data and outcome of a homogeneous group of patients undergoing pancreatic enucleation, since the immediate results of simple enucleations may be supposed to be different from those of atypical resection or influenced by synchronous major surgical procedures.

\section{Statistical analysis}

An in-depth analysis of PF with respect to type of resection, modality of section of pancreatic parenchyma, management of pancreatic enucleated surface after tumor extirpation, and the use of somatostatin analogue was performed. Two-tailed Fisher exact test was used to compare categorical data. Considering the small sample of patients with PF and the non-significant difference of PF rate for any of the tested variables, a multivariable analysis and logistic regression to assess any relative risk were not done. A $p$ value $\leq 0.05$ was considered significant. All statistical analyses were performed with SPSS 13.0 (SPSS, Inc., Chicago, IL).

\section{Results}

Starting from 1996, 33 consecutive patients ( 22 females) underwent laparoscopic pancreatic enucleations/atypical resections. Patients' mean age was 54.6 years (range: $26-77$ years), and mean body mass index $25.2 \mathrm{~kg} / \mathrm{m}^{2}$ (range: $18.4-37.6 \mathrm{~kg} / \mathrm{m}^{2}$ ). Eighteen patients were classified as ASA I, 10 ASA II and 5 ASA III.

Location of the 33 pancreatic tumors (24 benign and 9 malignant) is reported in Table I. The mean maximum diameter was $21 \mathrm{~mm}$ (range: 5-60 mm).

According to the nature of the pancreatic tumor, various preoperative diagnostic tools were performed. Computed tomography (CT) scan enabled the identification of the lesion in 30/33 cases, and mag- 
Table I. Location of lesions with special focus on converted procedures

\begin{tabular}{|c|c|c|c|c|}
\hline Location & $\begin{array}{l}\text { No. of } \\
\text { cases }\end{array}$ & $\begin{array}{l}\text { Converted } \\
\text { procedures }\end{array}$ & $\begin{array}{l}\text { Histopathology of the tumor } \\
\text { (converted procedures) }\end{array}$ & $\begin{array}{l}\text { Reason for } \\
\text { conversion }\end{array}$ \\
\hline \multirow[t]{4}{*}{ Head $^{*}$} & \multirow[t]{4}{*}{12} & \multirow[t]{4}{*}{$4^{\ddagger}$} & Metastasis from renal cancer & Negative IUS \\
\hline & & & $\begin{array}{l}\text { Malignant NET of the duodenum infiltrating } \\
\text { the pancreatic head }\end{array}$ & Oncological \\
\hline & & & Schwannoma $^{\dagger}$ & Bleeding \\
\hline & & & Adenocarcinoma of the distal choledochus (pT1NO) & Technique \\
\hline \multirow[t]{2}{*}{ Uncus $^{\ddagger}$} & \multirow[t]{2}{*}{7} & \multirow[t]{2}{*}{2} & Serous cystadenoma & Technique \\
\hline & & & IPMN & Bleeding \\
\hline Neck & 7 & 1 & NET & Oncological§ \\
\hline Body-tail & 7 & - & - & - \\
\hline Total & 33 & $7^{\ddagger}$ & See above & See above \\
\hline
\end{tabular}

NET - neuroendocrine tumor, IPMN - intraductal papillary mucinous neoplasm, IUS - intraoperative ultrasound; *an adenocarcinoma of the distal choledochus and a NET of the duodenum are included, ${ }^{\dagger}$ the nature of the tumor was unknown at surgery, ${ }^{\ddagger}$ one lesion at the head-uncus junction was considered as belonging to the uncus, Sintraoperative US erroneously showed multiple preoperatively undetected liver metastasis (histology showed the benign nature of the tumor and normal liver parenchyma)

netic resonance imaging (MRI) in 11/14. Echoendoscopy was performed in 26 cases, localizing and characterizing the tumor in 25 cases. Echoendoscopyguided biopsy/aspiration was positive in 6 cases out of 8.

\section{Surgical technique}

The patient was positioned in a $30^{\circ}$ anti-Trendelenburg position with the operating surgeon between the legs, the assistant surgeon at his left and the nurse on the right. Pneumoperitoneum was induced $(12 \mathrm{~mm} \mathrm{Hg})$ by a Veress needle introduced in the umbilical region or left hypochondrium. A $0^{\circ}$ laparoscope held by a robotic arm under vocal control (Aesop ${ }^{\circledR}$, Computer Motion, Santa Barbara, California, USA/ViKY ${ }^{\circledR}$, EndoControl Medical, La Tronche, France), bipolar electrocautery forceps, scissors and, sporadically in 5 patients, harmonic scalpel (Ultracision ${ }^{\circledR}$, Ethicon Endo-Surgery, Cincinnati, Ohio, USA/SonoSurg ${ }^{\circledR}$, Olympus KeyMed, Southend-on-Sea, Essex, UK) were used during dissection and meticulous hemostasis.

Whenever deemed useful (in 26/33 patients), intraoperative laparoscopic ultrasound (US) (Diagnostic Ultrasound System $3535^{\circledR}$, B\&K Medical, Naerum, Denmark) was used in order to localize the tumor within the pancreatic parenchyma and to define its connections with vessels and the main pancreatic duct.

\section{Right-sided procedures (pancreatic head-uncus)}

Four or five trocars (one/two $12 \mathrm{~mm}$ and two/ three $5 \mathrm{~mm}$ ) are inserted according to Figure 1 (the fifth, in the upper midline, is normally added when the right colon has to be mobilized after US exploration). The gastrocolic ligament is sectioned. In the case of tumors located deeply in the parenchyma or in the posterior aspect of the head-uncus, a laparoscopic Kocher maneuver is performed.

The operating surgeon moves to the left side of the patients in order to perform US. The table is moved to a supine, $0^{\circ}$ position and then laterally tilted $15^{\circ}$ "right side up". If the lesion is resectable on US, a $5 \mathrm{~mm}$ trocar is introduced into the right hypochondrium. Depending on tumor location and size, the superior margin of the pancreas is dissected appropriately.

The operating surgeon moves back to the between-the-legs position, the table is repositioned in a $30^{\circ}$ anti-Trendelenburg position (with no lateral tilt) and tumor resection (enucleation or atypical resection) in an adequately freed pancreatic parenchyma is performed.

\section{Left-sided procedures (pancreatic neck-body-tail)}

Six trocars (two $12 \mathrm{~mm}$ and four $5 \mathrm{~mm}$ ) are introduced according to Figure 2. The table is tilted "left 


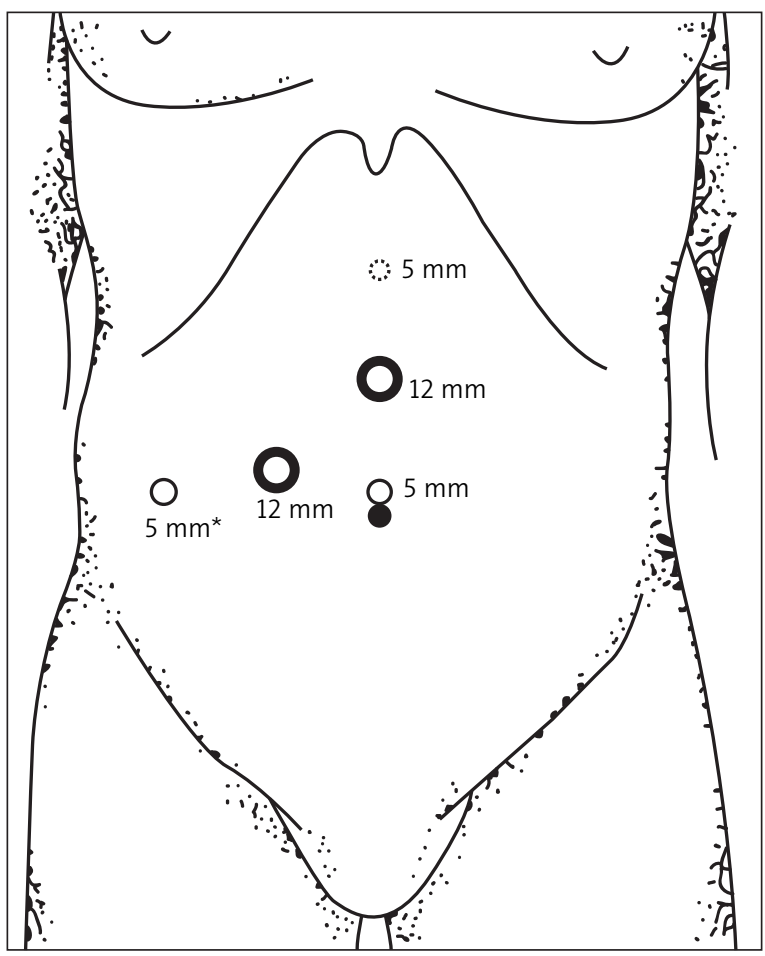

Figure 1. Trocar position* for right-sided procedures (head-neck-uncus)

*The $5 \mathrm{~mm}$-trocar in the right hypochondrium is added after laparoscopic US has confirmed the resectability of the tumor.

(dotted line) - trocar added during the procedure when needed

side up" $0^{\circ}$ to $15^{\circ}$, to achieve the best visualization. The gastrocolic ligament is sectioned and laparoscopic US performed in order to assess the resectability of the tumor with respect to the main pancreatic duct. Depending on tumor location and size, the superior and inferior margins of the pancreas are dissected appropriately. If the lesion is resectable and located at an adequate distance from the main pancreatic duct, an enucleation is carried out. Alternatively, a spleen-preserving distal pancreatic resection is performed.

\section{Tumor extirpation (enucleation, atypical resection)}

Bipolar electrocautery and (in 5 cases) a harmonic scalpel were used to dissect the lesion from the pancreatic parenchyma (enucleations) or to section the pancreas (atypical resections). Depending on location and size of the tumor, characteristics of the parenchyma and tendency to bleed, the operating surgeon arbitrarily decided to suture the pancreas or not, as

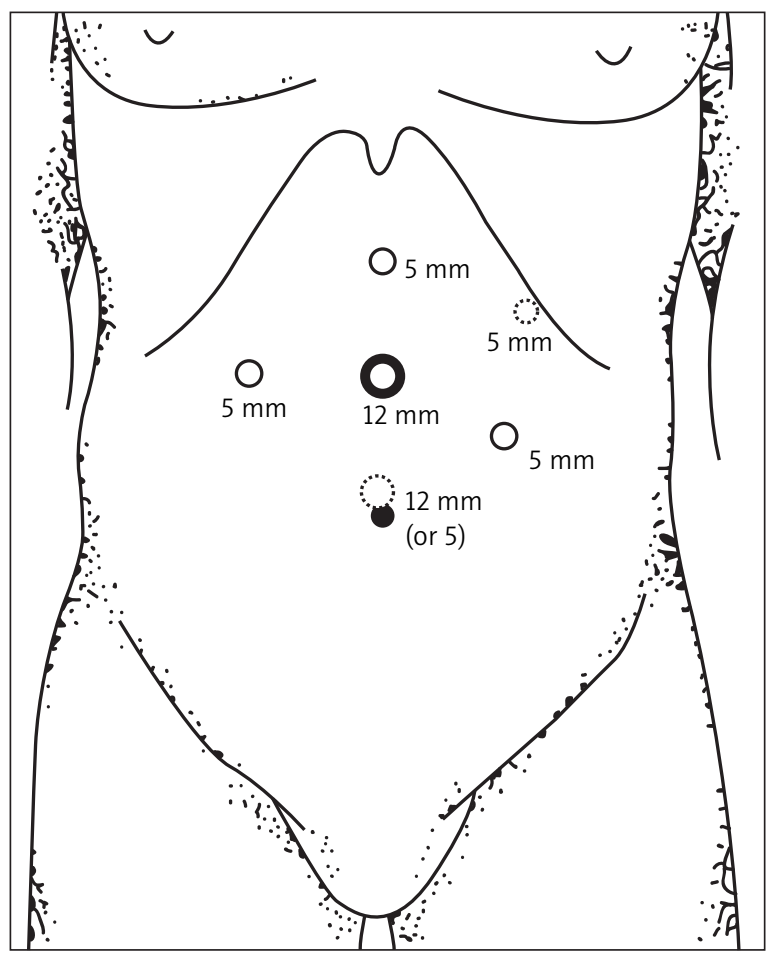

Figure 2. Trocar position for left-sided procedures (body-tail)

(dotted line)-trocars added during the procedure when needed

well as to place various products in the cutting surface. A drain was placed in $24 / 33$ cases.

Twenty-nine pancreatic enucleations and 4 atypical resections were carried out. Atypical resection was preferred to enucleation owing to the preoperatively diagnosed malignant nature of the tumor and/or its location. The four atypical resections included: a 4-cm intraductal papillary mucinous neoplasm (IPMN) of the pancreatic head (histology revealed the benign nature of the lesion); a $25-\mathrm{mm}$ gastrinoma of the second duodenum, resected by transduodenal resection (frozen section revealed the malignant nature of the lesion), followed by resection of the second-third part of the duodenum and the inferior part of the pancreatic head; a 3-cm mass of the pancreatic head of uncertain nature treated by atypical resection and lymphadenectomy along the hepatic artery (at pathology: schwannoma); a 12-mm cholangiocarcinoma of the distal choledochus which was resected with the surrounding pancreatic parenchyma (PD was considered high risk for an 87-year- 
Table II. Early postoperative outcome

\begin{tabular}{|lccccc|}
\hline $\begin{array}{l}\text { Procedures } \\
\text { (no. of patients) }\end{array}$ & \multicolumn{3}{c}{ Postoperative morbidity } & Postoperative & $\begin{array}{c}\text { Median hospital } \\
\text { mortality } \\
\text { stay [days] } \\
\text { (mean; range) }\end{array}$ \\
\hline All procedures (33) & $20-60 \%(15-45 \%)$ & $14^{\dagger}-42 \%$ & $10-30 \%$ & - & $19 \neq(28 ; 4-124)$ \\
\hline $\begin{array}{l}\text { Enucleations without } \\
\text { other major procedures (22) }\end{array}$ & $14-63 \%(9-41 \%)$ & $10-45 \%$ & $8-36 \%$ & - & $18(22 ; 4-64)$ \\
\hline
\end{tabular}

*HPB-specific - hepato-, pancreato-, biliary-specific complications, ${ }^{\dagger}$ a case of major bleeding requiring emergency splenectomy on postoperative day 1 after enucleation associated with distal pancreatectomy is included, ${ }^{\ddagger}$ hospital stay for uncomplicated procedures was 8 days (range: 4-12 days)

Table III. Intraoperative results

\begin{tabular}{|lccc|}
\hline Type of procedure (no. of patients) & $\begin{array}{c}\text { Mean operative time [min] } \\
\text { (median; range) }\end{array}$ & $\begin{array}{c}\text { Mean blood loss [ml] } \\
\text { (median; range) }\end{array}$ & $\begin{array}{c}\text { Conversions } \\
n(\%)\end{array}$ \\
\hline All procedures (33) & $189(150 ; 60-450)$ & $133(0 ; 0-500)$ & $7(21)$ \\
\hline $\begin{array}{l}\text { Enucleations without other } \\
\text { major procedures (22) }\end{array}$ & $144(132 ; 60-240)$ & $112^{*}(0 ; 0-1500)$ & $2(10)$ \\
\hline
\end{tabular}

*Mean intraoperative bleeding is $26 \mathrm{ml}$ if one case of massive portal bleeding (1500 $\mathrm{ml}$ ) requiring conversion for hemostasis is excluded

old, ASA III patient). The last three procedures were converted to an open approach (see Table I for the details of converted procedures).

Twenty-one patients out of 33 underwent a total of 27 associated procedures. Of these, 9 were major procedures, including distal pancreatectomy with splenic preservation (2), Ivor-Lewis oesophagectomy (1 patient), right hepatectomy (1), resection of the distal choledochus and choledocho-jejunal anastomosis (1), duodenotomy/rrhaphy and ampullectomy (2), duodenotomy/rrhaphy (1), suture of the choledochus (1). Minor procedures were 18 , including cholecystectomy (8), adhesiolysis (4), atypical liver resection/ hepatic biopsy (3), lymphadenectomy along the hepatic artery (1), omental partial resection (1), celiac ganglion resection (1). Overall, 11 patients underwent complex procedures (atypical resection or enucleation associated with major surgical procedures), whereas 22 patients underwent simple enucleations.

Intraoperative data (duration of surgery, conversion rate and blood loss) are reported in Table III. In 7 cases (21\%), the procedure was converted to laparotomy (they were cases no. 1, 2, 4, 5, 6, 21 and 32 of the series). Four conversions occurred for benign pathologies (1 IPMN, 1 schwannoma, 1 serous cystadenoma, 1 gastrinoma) and 3 for malignancy (renal metastases, malignant neuroendocrine tumor of the second duodenum, adenocarcinoma of the chole- dochus). Converted procedures included 3/4 atypical resections and 4/29 enucleations: 2 of the latter were associated with major procedures (laparoscopic right hepatectomy, laparoscopic distal pancreatectomy) and 1 was performed for a $25-\mathrm{mm}$ serous cystadenoma of the uncus. One additional case (case no. 26 of the series - enucleation of a $25-\mathrm{mm}$ insulinoma of the posterior aspect of the pancreatic head) required a minilaparotomy to perform a duodenotomy in order to reposition a dislocated biliary stent and is not included in conversions.

The results of pathology examination are reported in Table IV. Nine patients out of 33 had a preoperative histological diagnosis. Of the remaining 24 patients without a preoperative histology, pathologist examination confirmed the suspected preoperative diagnosis in 4 cases, changed the preoperative diagnosis in 2 ("IPMN" into "cystic canalar structure"), and led to the definition of the degree of malignancy in 17 cases (e.g.: "gastrinoma of uncertain behavior" in "benign gastrinoma"). In 1 case, a pancreatic tumor was accidentally discovered during surgery. Excluding this latter case, definitive histology gave a determinant contribution to defining the nature of the tumor in $21 / 32$ cases (66\%).

In 1 case, the pancreatic surgical margin was not free: a 42-year-old female patient undergoing pancreatic enucleation and two liver atypical resections 
Table IV. Histology of resected pancreatic tumors

\begin{tabular}{|lc|}
\hline Nature of the tumor (definitive histology) & $\begin{array}{c}\text { No. of } \\
\text { patients }\end{array}$ \\
\hline Benign: & 24 \\
\hline IPMN & 8 \\
\hline NET & 8 \\
\hline - Undifferentiated or tissue typing not performed & 5 \\
\hline Insulinoma & 2 \\
\hline - Gastrinoma & 1 \\
\hline Serous cystadenoma & 4 \\
\hline Mucinous cystadenoma & 2 \\
\hline Pancreatic cyst & 1 \\
\hline Schwannoma & 1 \\
\hline Malignant: & 9 \\
\hline NET & 4 \\
\hline M Undifferentiated or tissue typing not performed & 4 \\
\hline Metastases from renal carcinoma & 4 \\
\hline Adenocarcinoma of the distal choledochus & 1 \\
\hline
\end{tabular}

NET - neuroendocrine tumor, IPMN - intraductal papillary mucinous neoplasm

for a neuroendocrine tumor of the pancreatic neck with synchronous liver metastasis diagnosed by intraoperative ultrasound. Definitive histology showed a R1 resection of a pT3 N1 M1 tumor (one positive gastroepiploic lymph node, two liver metastases of $4 \mathrm{~mm}$ and $5 \mathrm{~mm}$ ). During the postoperative course, the patient developed an infected necrotic pancreatitis and underwent necrosectomy by laparotomy. No other surgery was programmed with the purpose of oncological radicality. At the last two follow-ups (73 and 84 months from surgery), the patient presented multiple, "stable" liver metastasis.

In all cases, at least one imaging technique was performed before discharge (CT scan in 30 cases, US in 19). All patients were reviewed at least once during the 2 weeks after surgery (follow-up differed according to the nature of the tumor and the outcome of the patient). One patient was lost at follow-up, at 81 months. Overall, mean follow-up lasted 61 months (range: 11-176 months).

Post-operative outcomes (morbidity, mortality, duration of hospital stay) are reported in Table II. The details of overall postoperative complications, PF and treatment are reported in Table V. The analysis of PF with respect to type of resection, modality of section of pancreatic parenchyma, management of pancreatic raw surface after tumor extirpation and use of somatostatin analogue is reported in Table VI.

Sixteen patients underwent a total of 25 postoperative procedures, including 6 patients undergoing 10 surgical interventions ( 8 in the first postoperative month and 2 thereafter). At the last follow-up, three patients were dead: 1 patient died of metastatic esophageal cancer 6 months after esophagectomy and enucleation of a preoperatively undetected IPMN of the pancreatic body; one patient died of metastatic adenocarcinoma of the body of the pancreas 23 months after enucleation of "cystic canalar structure" of the pancreatic neck (the re-examination of the specimen and pre-/postoperative imagery did not identify any neoplastic lesion in the excised tissue/ pancreatic remnant); the last patient died at the age of 85 of an unrelated cause. Four patients are alive with metastatic disease: 1 patient with stable left surrenal and left kidney recurrence 94 months after an enucleation of renal adenocarcinoma metastasis; 1 patient with stable liver metastases 84 months after enucleation and liver metastasectomy of a malignant neuroendocrine tumor associated with synchronous liver metastasis; one patient undergoing laparoscopic jejunal resection for an intraperitoneal recurrence of an unrelated colon adenocarcinoma 33 months after enucleation of renal adenocarcinoma metastasis; the last patient in a terminal stage with diffuse liver metastases 28 months after the enucleation of a malignant neuroendocrine tumor.

\section{Discussion}

Unlike major pancreatic surgery, laparoscopic minor pancreatic resections are increasingly performed worldwide. Several reasons may explain why: - minor pancreatic procedures do not usually involve the dissection of major abdominal vessels or the performance of anastomoses, which are still considered difficult tasks to be accomplished laparoscopically;

- since they are mostly performed for benign lesions, the lack of tactile feedback is less important as the issue of surgical margin virtually does not exist, and lymphadenectomy is not required; 
Table V. Postoperative complications

\begin{tabular}{|c|c|c|c|c|}
\hline Complication* & $\begin{array}{l}\text { everity of complication } \\
\text { Clavien-Dindo, 2004) }\end{array}$ & $\begin{array}{l}\text { Severity of PF } \\
\text { (ISGPF, 2005) }\end{array}$ & Treatment† & $\begin{array}{l}\text { Hospital } \\
\text { stay }\end{array}$ \\
\hline Pleural collection & IIla & - & Thoracic puncture & 17 \\
\hline $\begin{array}{l}\text { Hemoperitoneum, necrosis } \\
\text { of distal choledochus }\end{array}$ & $\| I l b$ & - & Splenectomy, biliary drain (Kehr) & 41 \\
\hline $\begin{array}{l}\text { 1. Pancreatico-duodenal fistula, } \\
\text { necrotic pancreatitis } \\
\text { 2. Early incisional hernia } \\
\text { 3. Abscess }\end{array}$ & IV & C & $\begin{array}{l}\text { 1. Necrosectomy, duodenorrhaphy, } \\
\text { gastrostomy, jejunostomy } \\
\text { 2. Prosthetic repair } \\
\text { 3. Drainage }\end{array}$ & 124 \\
\hline Sub-hepatic collection & IIla & - & Percutaneous drainage & 29 \\
\hline PF (peri-pancreatic collection) & IIla & C & Percutaneous drainage & 20 \\
\hline Biliary fistula & IIla & - & Biliary stent & 55 \\
\hline $\begin{array}{l}\text { Hemorrhage due to necrotic } \\
\text { pancreatitis }\end{array}$ & IV & - & $\begin{array}{l}\text { Pyloric artery stump hemostasis, } \\
\text { necrosectomy }\end{array}$ & 28 \\
\hline PF (intra-peritoneal collection) & IIla & C & Percutaneous drainage & 64 \\
\hline $\begin{array}{l}\text { 1. Hemoperitoneum } \\
\text { 2. Infected PF (intra-peritoneal abscess) } \\
\text { 3. Infected necrotic pancreatitis }\end{array}$ & s) & C & $\begin{array}{l}\text { 1. Right colic artery hemostasis } \\
\text { 2. Percutaneous drainage } \\
\text { 3. Necrosectomy }\end{array}$ & 47 \\
\hline Biliary fistula $\ddagger$ & $\|$ & - & Biliary stent (2) & 33 \\
\hline PF (peri-pancreatic collection) & Illa & C & Percutaneous drainage & 31 \\
\hline Pancreatic pseudocyst & $I I I b$ & - & Biliary stent (2), cysto-gastrostomy & 16 \\
\hline $\begin{array}{l}\text { 1-2. Hematoma } \\
\text { 3. Duodenal fistula§ }\end{array}$ & IIla & - & $\begin{array}{l}\text { 1-2. Drainage (2) } \\
\text { 3. Percutaneous drainage }(2)^{\S}\end{array}$ & $40 \S$ \\
\hline PF (peri-pancreatic collection) & IIla & C & Percutaneous drainage & 7 \\
\hline PF (drained) & IIla & B & Wirsung stent & 42 \\
\hline Strangulated incisional hernia & $\mathrm{IVa}$ & - & Hernia repair (no resection) & 22 \\
\hline Retro-gastric collection & IIla & - & Percutaneous drainage & 13 \\
\hline PF (peri-pancreatic collection) & $\|$ & All & - & 19 \\
\hline PF (retro-gastric collection) & $\|$ & All & - & 33 \\
\hline PF (peri-pancreatic collection) & $\|$ & All & - & 38 \\
\hline
\end{tabular}

PF-pancreatic fistula; *the last 3 patients listed were retrospectively classified as having a pancreatic fistula since they presented a peripancreatic, sub-hepatic and intraperitoneal collection at abdominal CT scan, although the collection was not drained (and consequently amylase was not dosed), tenteral nutrition, antibiotic therapy and somatostatin analogues as the treatment of pancreatic fistula are not considered, "the patient also had portal vein partial thrombosis treated by intravenous heparin administration, Sthe patient was re-hospitalized for 17 days, Ilin the last three reported cases, the diagnosis of pancreatic fistula was made only on a CT scan basis, since the collection was not drained and pancreatic enzymes were not dosed

- modern tools (harmonic scalpel, Ligasure ${ }^{\circledR}$ ) allow for a blood-sparing dissection of the pancreas, and may be supposed to be useful during pancreatic tumor extirpation together with recently introduced products proposed for the management of pancreatic raw surface.
Although such technological progress is favoring the diffusion of increasingly difficult laparoscopic procedures [20], nevertheless, the advantages shown by laparoscopy in other fields still have to be confirmed in minor pancreatic surgery. Also, owing to the heterogeneity and exiguity of series, operating time is report- 
Table Vl. Analysis of pancreatic fistula onset with respect to type of resection, modality of section of pancreatic parenchyma, management of pancreatic resection margin and use of somatostatin analogue

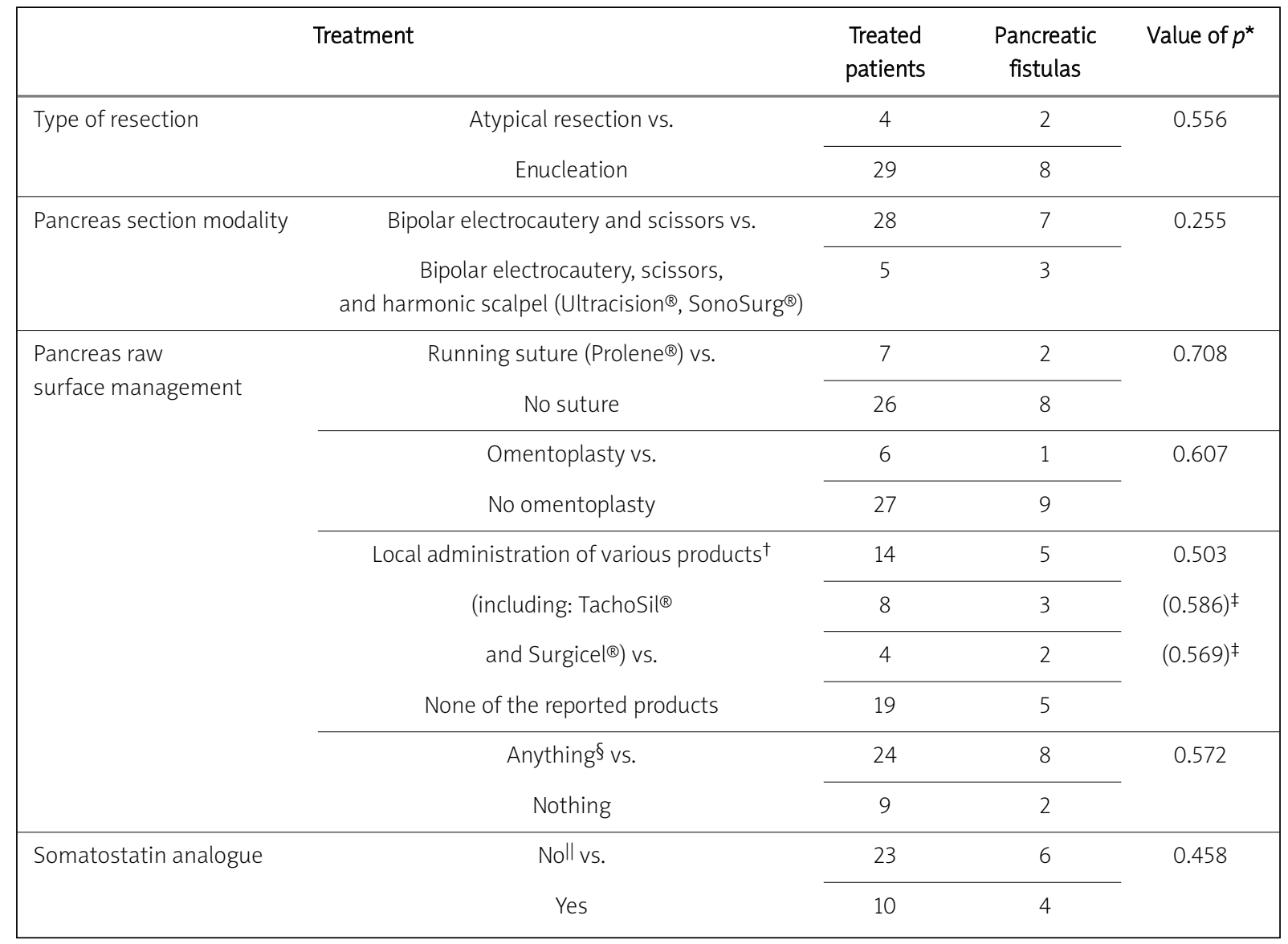

${ }^{\star}$ Fisher's exact test, ${ }^{+}$including Tachosil ${ }^{\circledR}$, Surgice ${ }^{\circledR}$ or Floseal ${ }^{\circledR},{ }^{\ddagger}$ compared to no local administration of any products, $\$$ Including running suture $\left(\right.$ Prolene $\left.{ }^{\circledR}\right)$, omentoplasty, and local administration of Tachosil ${ }^{\circledR}$, Surgicel ${ }^{\circledR}$ or Floseal ${ }^{\circledR}$, IIsomatostatin analogue administration starting after the onset of pancreatic fistula is not considered

ed to vary from 50 min to 405 min [5], conversion rate from 0 to $75 \%$, morbidity (PF) from 0 to $78 \%[11,21]$, and postoperative stay from 1 to 67 days $[4,21]$. When considering the mere 6 articles reporting series of at least 10 patients $[4,5,7]$, the interest of their results is limited by lack of homogeneity, since they report the results of multicentric series [4, 7], or include pancreatic enucleations associated with synchronous major surgery [5] or patients undergoing major pancreatic resections $[4,5,7,8]$. Pancreatic procedures present peculiar issues which do not allow for a cumulative analysis: enucleation is generally considered a high morbidity/low mortality procedure with a major postoperative concern, PF [22], whereas the main issues of major pancreatic surgery are postoperative diabetes [23], splenic preservation (distal pancreatectomy) [2], anastomotic leakage and mortality (PD) [23].
Since our series also includes patients undergoing various pancreatic procedures (enucleation and atypical resections) and/or synchronous major surgery, with the aim of a more precise evaluation of enucleation results, some data (operating time, conversion, blood loss, morbidity, and hospital stay) are analyzed both in the whole series and separately for simple enucleations. The results of Pierce et al. [13], reporting the mean operating time as doubling when enucleation is associated with major procedures ( $85 \mathrm{~min}$ vs. $177 \mathrm{~min}$ ), and the extremely wide operating time range reported by Røsok et al. [5] (50-405 min), who included patients undergoing synchronous major surgery, to some extent support our attitude. However, since PF is unlikely to be due to associated surgical procedures, the analyses concerning PF (Tables $V$ and $\mathrm{VI}$ ) are proposed only in the whole series. Finally, 
since the aim of the paper was to evaluate the results of laparoscopic minor pancreatic resections, preoperative workup, which varied considerably depending on the nature of the tumor, has been deliberately omitted.

Our results confirm the technical feasibility and safety of the laparoscopic approach to enucleations, whereas it still seems at least questionable when a wider pancreatic resection is needed, as suggested by the outcome of the 4 atypical resections (3 conversions, 2 PFs). Over 15 years, the continuously improving technique, in addition to a better indication for the laparoscopic approach, has led to a decrease in the conversion rate of minor pancreatic surgery (only 2 of the last 27 procedures - 7\%), with only two intraoperative complications (bleeding) requiring conversion.

An improved, standardized surgical technique, including the changing position of the surgical team during pancreatic head enucleations, results nowadays in an ergonomic position for the operating surgeon throughout the entire procedure. While a few surgeons prefer a lateral position [8, 12], the majority opt for a more classic between-the-legs position $[4,5,7,9-11,21]$. In our experience, in the case of pancreatic head/neck/uncus tumors, surgeon positioning on the left side of the patient may facilitate laparoscopic US and pancreas dissection from supra, retropancreatic vessels before the enucleation, which may then be easily achieved from a between-the-legs position. As proposed by others, we are used to tilt the table from a supine to a reverse-Trendelenburg position $[24,25]$ or laterally, towards the right $[4,7,12]$ or the left $[4,12]$ according to the patient's anatomy. Such a "dynamic" attitude during the procedure makes the presence of two monitors [25] useful.

Trocar placement and number vary considerably in the literature. Although most authors seemingly adopt the same trocar placement regardless of tumor location [5, 26, 27], our procedures for left- and rightsided tumors change radically. A "radial" placement towards the left hypochondrium in the first case (Figure 1), similar to that described by other authors $[13,25]$, and an original "reverse L" placement towards the right hypochondrium in the second one (Figure 2) afford us the best exposure of the operating field. Our approach is consistent with that of the literature, where the use of three $[4,12]$ to six trocars $[4,11]$ is reported. Indeed, since we believe that ergonomics in the case of a potentially long-lasting procedure should be a priority and that trocar number is not a relevant issue in these patients, we do no hesitate to insert 5 or 6 trocars, if needed. Good visualization of the pancreas is achieved by a $0^{\circ}$ laparoscope. The latter is preferred since it allows for easier use of the camera-holding robotic arm under voice control (Aesop ${ }^{\circledR} / \mathrm{ViKY}^{\circledR}$ ). A $30^{\circ}$ laparoscope $[9,12,24$, 26] may be useful during the dissection of retro-pancreatic structures; as described before, we compensate for the lack of side vision by moving to the left side of the patient.

The overall mean operating time (183 $\mathrm{min})$ is among the longest ones reported so far (180 min [26], $248 \mathrm{~min}$ [13]). The mean operating time of simple enucleations (144 min) is slightly longer than that reported in the main series, which ranges from $85 \min$ to $140 \min [4,5,7,9,10]$. A significant number of procedures carried out for tumors located in the pancreatic head/uncus (19/33), which are considered more difficult to approach by laparoscopy [28], may explain this difference. Mean blood loss (112 ml), which is consistent with the $55-255 \mathrm{ml}$ averaged by most authors $[4,5,9,10,28]$, falls to $26 \mathrm{ml}$ if we exclude one case of massive intraoperative bleeding $(1500 \mathrm{ml})$. Similarly to lihara and Obara [12], who report a similar, very low blood loss $(15 \mathrm{ml})$, we perform the gastrocolic ligament division and pancreatic dissection by bipolar electrocautery and harmonic scalpel. Operating time and blood loss in our series are consistent with those observed for enucleation by the open approach, which are reported to be in the range of 121-199 $\mathrm{min}[22,24,29]$ and $114-115 \mathrm{ml}[27,29]$, respectively.

The conversion rate was $21 \%$ (7/33) overall, whereas it was $9 \%$ (2/22) for simple enucleations, this latter figure being consistent with those of the literature [4, $5,7-10]$. Our overall conversion rate matches the $25 \%$ reported by Luo [9] (including two procedures converted to a hand-assisted approach), but is higher than the $5-12.5 \%$ reported by others $[4,5,7,10]$. Nevertheless, it should be noted that 5 conversions occurred during the first 6 procedures, performed in the mid-nineties, when the indication for laparoscopy was not codified. Moreover, the series includes 9 patients with neoplastic disease (in 2 cases the conversion was to some extent programmed for oncological reasons on the basis of intraoperative findings), and 11 undergoing complex procedures. Significantly, the conversion rate of the last 27 procedures fell to $7 \%$ (2 patients). 
Interestingly, the majority of conversions (6/7) occurred for right-sided enucleations (head-uncus), whereas only one procedure was converted among those performed for neck-body-tail lesions. Whether right-sided pancreatic tumors should be approached laparoscopically is a matter of debate [5, 10, 12, 24]. Several authors report conversions to laparotomy during enucleations of lesions arising in the head of the pancreas [7, 9, 13, 26] or uncus [9], and attribute those conversions to a non-localization of the lesion or its difficult dissection from superior mesenteric vessels, the portal vein, common bile duct or duodenum.

In our series, we were unable to localize the tumor, preoperatively or intraoperatively, in only one case, and the remaining conversions were due to technical difficulty or for oncological reasons. We share the opinion of most authors, who perform intraoperative US routinely [5, 8, 24-26], and not sporadically $[7,11]$, since it leads to the definition of tumor position/margins and its connections with the main pancreatic duct and major vessels. Intraoperative US, together with meticulous preoperative localization of the lesion $[7,8,12]$ and (in the case of rightsided tumors) complete mobilization of duodenum/ head of the pancreas by extended Kocher maneuver [27], are the key to the localization of virtually all tumors. We believe that the right-sided location of a pancreatic tumor should not contraindicate a laparoscopic approach despite the greater difficulty in performance.

The introduction of laparoscopy in pancreatic surgery has rekindled the debate about enucleation of tumors of malignant/uncertain nature. Phan et al. [30] report endocrine malignancy with infiltrated margins to be related to poor outcome, concluding that reoperation should be considered in those cases. Bassi et al. consider atypical resection [31] and a laparoscopic approach [19] to be unsuitable to treat pancreatic metastasis from renal adenocarcinoma, although no statistical difference emerged between atypical resections and major surgery in terms of survival [31]. A recent consensus on IPMN management suggests the standard pancreatic resection of those tumors [32]; nevertheless, in 2000, we first described the successful enucleation of IPMN [33] and, more recently, Blanc et al. reported no recurrence among 26 patients with IPMN undergoing enucleation [34]. In our series, no local recurrence from malignant tumor was reported, including the only patient with infiltrated margins at histology, where severe pancreati- tis and the synchronous presence of liver and lymph node metastasis prevented us from performing any further, more radical surgery. Based on our experience in laparoscopic and open pancreatic enucleation $[16,17,33]$, we believe that a thorough preoperative work-up and intraoperative US may allow for laparoscopic enucleation/atypical resection of malignant/ uncertain tumors in selected patients, as confirmed by others $[4,5,8,13]$. The exiguous number of patients with malignant disease treated by enucleation so far clearly does not allow for any definitive conclusions.

Another theoretical advantage of a mini-invasive approach to pancreatic tumors is probably underestimated. In a not-inconsiderable number of cases, pancreatic tumors (endocrine tumors, IPMN, mucinous adenoma) are of uncertain nature. Moreover, they often present difficulty at biopsy, owing to their small size or location, embedded within a solid, retroperitoneal organ. In these cases, surgery may result as being both diagnostic and therapeutic. If we consider that, in our series, 1) no tumor was understaged/misdiagnosed at pre- or intra-operative examination, and that laparoscopy allowed for 2) exploration of the abdominal cavity (hence ruling out the presence of carcinosis, synchronous tumors/metastases etc.), 3) extirpation of the tumor, 4) the specification of tumor histology in two thirds of the cases and, concomitantly, 5) the avoidance of major resections and extensive laparotomy, the advantages of a mini-invasive approach can easily be appreciated.

As confirmation of the common belief that pancreatic enucleation is a low-mortality/high-morbidity procedure, no patient died, roughly half of the patients had complications and one third had a PF. Interestingly enough, morbidity, rate of hepato-pancreato-biliary-specific complications and rate of PF were similar when evaluating the outcome of patients undergoing simple enucleations and the whole series (Table IV), confirming the main role of pancreatic dissection/section in morbidity, regardless of associated procedures. The morbidity (60\%) and PF rate $(30 \%)$ seem high when compared to those reported in bigger series [4, 5, 7-10], in the range $17-42 \%$ and $13-35 \%$, respectively. Indeed, methods of evaluation of morbidity and PF differ from ours, the ISGPF classification being used in only two studies $[5,10]$ and the Clavien-Dindo classification of morbidity in none. Moreover, only one paper reports the routine use of a peripancreatic drain [10], and none mentions 
postoperative imaging of the retroperitoneal region before discharge. For all these reasons, we believe that the incidence of morbidity and PF may be underestimated in some cases. The results of DeOliveira et al. [23], who report morbidity after pancreatic surgery to rise to $58.5 \%$ when Clavien-Dindo criteria are strictly applied, seem to confirm that different methods of evaluation may substantially affect perioperative morbidity. Thus, although some authors maintain that a better (laparoscopic) view may allow for a more precise dissection and reduce the fistula rate [10], we believe that laparoscopy does not reduce the PF rate of enucleations, as "traditional" series report a similar $27-38 \%$ PF rate $[22,29]$.

Since PF was not related to type of extirpation, modality of pancreatic section, management of pancreatic raw surface or the preventive use of somatostatin analogues, our results do not support any of those treatments. In general, laparoscopic series [4, 5, 7-10] (including the present one) present the typical bias of a retrospective study of a small series over a relatively long period and do not allow for an evaluation of such treatments in reducing the frequency of PF. Nor do results in large series of patients operated on by laparotomy allow for a definition of the ideal treatment. The harmonic scalpel [35], and, more recently, Ligasure ${ }^{\circledR}$ [36], have been proposed for the section of pancreatic parenchyma, but have not entered clinical practice. Various managements of the pancreatic remnant, including suturing [37] and fibrin glue application [38], have been reported as not reducing the rate of PF after various pancreatic resection procedures.

Whether somatostatin analogues may reduce the rate of morbidity/PF after pancreatic surgery has been a matter of debate since the early nineties and is still unclear $[39,40]$. Unfortunately, these papers do not analyze the results of those treatments specifically after pancreatic enucleation. In general, based on recent literature and our results, it may be concluded that the ideal way of sectioning and managing the pancreas to minimize the rate of PF still has to be found.

As a consequence of the high rate of long-lasting complications (such as PF), the 18-day median hospital stay we report is higher than that described by other authors, which ranges from 4.4 to 11.8 days [4, $5,8,10,29]$. Interestingly, Sweet et al. [21] report the occurrence of a PF in 7/9 patients (78\%) after pan- creatic enucleation, and a mean hospital stay of 4.4 days ( 5 patients were discharged on postoperative day 1). Fernández-Cruz et al. [8], although 7 of their 20 patients (35\%) developed a PF, report a 5.5-day hospitalization with a maximum stay of 7 days, whereas Luo et al. [9] report a $25 \%$ rate of PF (4/16 patients) and 5.5-day hospital stay (range: 5-18 days). Probably, geographic differences in health systems and medical insurances as well as the availability of medical facilities for post-surgical convalescence, in addition to a different attitude in the management of PF, may explain such a difference in postoperative stay compared with our series. Indeed, such a "fast-track" approach reported by some authors may also be supposed to lead to an underestimation of in-hospital morbidity and PF, as enucleation-related complications may occur even after the first postoperative week. Since the mean hospital stay of our series matches that of patients undergoing pancreatic enucleation by traditional surgery, which ranges from 14 to 17.6 days [22, 27, 29], the length of hospitalization may not be considered as an element in favor of a laparoscopic approach in our experience.

\section{Conclusions}

The laparoscopic enucleation of pancreatic tumors is feasible and safe regardless of tumor location in pancreatic parenchyma, with no mortality, no extension of operating time, a high success rate and short hospitalization in some cases; conversely, it does not imply a reduction in complications (including PF) or overall hospital stay. Only technological upgrades in the means of pancreas section and its management will allow for the reduction of perioperative PF, morbidity and hospital stay, thus maximizing the potential advantages of a mini-invasive approach. Controlled randomized studies on larger series of patients will allow for an effective evaluation of the benefits of laparoscopic minor pancreatic resection.

\section{Acknowledgments}

This study was presented in an abstract form at the Annual Congress of the Society of American Gastrointestinal and Endoscopic Surgeons (SAGES), San Diego, CA (U.S.A.), March 7-10, 2012.

\section{References}

1. Gagner M, Pomp A. Laparoscopic pylorus-preserving pancreatoduodenectomy. Surg Endosc 1994; 8: 408-10. 
2. Cuschieri A, Jakimowicz JJ, van Spreeuwel J. Laparoscopic distal $70 \%$ pancreatectomy and splenectomy for chronic pancreatitis. Ann Surg 1996; 223: 280-5.

3. Palanivelu C, Jani K, Senthilnathan P, et al. Laparoscopic pancreaticoduodenectomy: technique and outcomes. J Am Coll Surg 2007; 205: 222-30.

4. Mabrut JY, Fernandez-Cruz L, Azagra JS, et al.; Hepatobiliary and Pancreatic Section (HBPS) of the Royal Belgian Society of Surgery; Belgian Group for Endoscopic Surgery (BGES); Club Coelio. Laparoscopic pancreatic resection: results of a multicenter European study of 127 patients. Surgery 2005; 137: 597-605

5. Røsok BI, Marangos IP, Kazaryan AM, et al. Single-centre experience of laparoscopic pancreatic surgery. Br J Surg 2010; 97 : 902-9.

6. Michalik M, Bobowicz M, Lech P, et al. Distal pancreatic resection via laparo-endoscopic single site surgery - development of the technique. Videosurgery Miniinv 2010; 5: 142-5.

7. Ayav A, Bresler L, Brunaud L, Boissel P; SFCL (Société Française de Chirurgie Laparoscopique); AFCE (Association Francophone de Chirurgie Endocrinienne). Laparoscopic approach for solitary insulinoma: a multicentre study. Langenbecks Arch Surg 2005; 390: 134-40.

8. Fernández-Cruz L, Cosa R, Blanco L, et al. Curative laparoscopic resection for pancreatic neoplasms: a critical analysis from a single institution. J Gastrointest Surg 2007; 11: 1607-21.

9. Luo Y, Liu R, Hu MG, et al. Laparoscopic surgery for pancreatic insulinomas: a single-institution experience of 29 cases. J Gastrointest Surg 2009; 13: 945-50.

10. Dedieu A, Rault A, Collet D, et al. Laparoscopic enucleation of pancreatic neoplasm. Surg Endosc 2011; 25: 572-6.

11. Jaroszewski DE, Schlinkert RT, Thompson GB, Schlinkert DK. Laparoscopic localization and resection of insulinomas. Arch Surg 2004; 139: 270-4.

12. lihara $M$, Obara T. Recent advances in minimally invasive pancreatic surgery. Asian J Surg 2003; 26: 86-91.

13. Pierce RA, Spitler JA, Hawkins WG, et al. Outcomes analysis of laparoscopic resection of pancreatic neoplasms. Surg Endosc 2007; 21: 579-86.

14. Castaing D, Vibert E, Ricca L, et al. Oncologic results of laparoscopic versus open hepatectomy for colorectal liver metastases in two specialized centers. Ann Surg 2009; 250: 849-55.

15. Gumbs AA, Bouhanna P, Bar-Zakai B, et al. Laparoscopic partial splenectomy using radiofrequency ablation. J Laparoendosc Adv Surg Tech A 2008; 18: 611-3.

16. Gumbs AA, Grès P, Madureira FA, Gayet B. Laparoscopic vs. open resection of noninvasive intraductal pancreatic mucinous neoplasms. J Gastrointest Surg 2008; 12: 707-12.

17. Gumbs AA, Grès P, Madureira F, Gayet B. Laparoscopic vs. open resection of pancreatic endocrine neoplasms: single institution's experience over 14 years. Langenbecks Arch Surg 2008; 393: 391-5.

18. Dindo D, Demartines N, Clavien PA. Classification of surgical complications: a new proposal with evaluation in a cohort of 6336 patients and results of a survey. Ann Surg 2004; 240: 205-13.

19. Bassi C, Dervenis C, Butturini G, et al.; International Study Group on Pancreatic Fistula Definition. Postoperative pancreatic fistula: an international study group (ISGPF) definition. Surgery 2005; 138: 8-13.

20. Costi R, Denet C, Sarli L, et al. Laparoscopy in the last decade of the millennium. have we really improved? Surg Endosc 2003; 17: 791-7.

21. Sweet MP, Izumisato Y, Way LW, et al. Laparoscopic enucleation of insulinomas. Arch Surg 2007; 142: 1202-4.

22. Crippa S, Bassi C, Salvia R, et al. Enucleation of pancreatic neoplasms. Br J Surg 2007; 94: 1254-9.

23. DeOliveira ML, Winter JM, Schafer M, et al. Assessment of complications after pancreatic surgery: a novel grading system applied to 633 patients undergoing pancreaticoduodenectomy. Ann Surg 2006; 244: 931-7.

24. Karaliotas C, Sgourakis G. Laparoscopic versus open enucleation for solitary insulinoma in the body and tail of the pancreas. J Gastrointest Surg 2009; 13: 1869.

25. Assalia A, Gagner M. Laparoscopic pancreatic surgery for islet cell tumors of the pancreas. World J Surg 2004; 28: 1239-47.

26. Berends FJ, Cuesta MA, Kazemier G, et al. Laparoscopic detection and resection of insulinomas. Surgery 2000; 128: 386-91.

27. Sa Cunha A, Beau C, Rault A, et al. Laparoscopic versus open approach for solitary insulinoma. Surg Endosc 2007; 21: 103-8.

28. Liu H, Peng C, Zhang S, et al. Strategy for the surgical management of insulinomas: analysis of 52 cases. Dig Surg 2007; 24: 463-70.

29. Kiely JM, Nakeeb A, Komorowski RA, et al. Cystic pancreatic neoplasms: enucleate or resect? J Gastrointest Surg 2003; 7: 890-7.

30. Phan GQ, Yeo CJ, Hruban RH, et al. Surgical experience with pancreatic and peripancreatic neuroendocrine tumors: review of 125 patients. J Gastrointest Surg 1998; 2: 472-82.

31. Bassi C, Butturini G, Falconi M, et al. High recurrence rate after atypical resection for pancreatic metastases from renal cell carcinoma. Br J Surg 2003; 90: 555-9.

32. Tanaka M, Chari S, Adsay V, et al.; International Association of Pancreatology. International consensus guidelines for management of intraductal papillary mucinous neoplasms and mucinous cystic neoplasms of the pancreas. Pancreatology 2006; 6: 17-32.

33. Sciaudone G, Perniceni T, Lévy P, et al. Enucleation of intraductal papillary-mucinous tumor of the head of the pancreas. Gastroenterol Clin Biol 2000; 24: 121-4.

34. Blanc B, Sauvanet A, Couvelard A, et al. Limited pancreatic resections for intraductal papillary mucinous neoplasm. J Chir (Paris) 2008; 145: 568-78.

35. Suzuki Y, Fujino Y, Tanioka Y, et al. Randomized clinical trial of ultrasonic dissector or conventional division in distal pancreatectomy for non-fibrotic pancreas. Br J Surg 1999; 86: 608-11.

36. Hartwig W, Duckheim M, Strobel O, et al. LigaSure for pancreatic sealing during distal pancreatectomy. World J Surg 2010; 34: 1066-70.

37. Nathan H, Cameron JL, Goodwin CR, et al. Risk factors for pancreatic leak after distal pancreatectomy. Ann Surg 2009; 250: 277-81.

38. Suc B, Msika S, Fingerhut A, et al.; the French Associations for Surgical Research. Temporary fibrin glue occlusion of the main pancreatic duct in the prevention of intra-abdominal complica- 
tions after pancreatic resection: prospective randomized trial. Ann Surg 2003; 237: 57-65.

39. Lai EC, Lau SH, Lau WY. Measures to prevent pancreatic fistula after pancreatoduodenectomy: a comprehensive review. Arch Surg 2009; 144: 1074-80.

40. Koti RS, Gurusamy KS, Fusai G, Davidson BR. Meta-analysis of randomized controlled trials on the effectiveness of somatostatin analogues for pancreatic surgery: a Cochrane review. HPB (Oxford) 2010; 12: 155-65.

Received: 8.08.2012, revised: 13.11.2012, accepted: 17.11.2012. 